\title{
Hysteroscopic assessment of patients with abnormal uterine bleeding: a prospective study at a tertiary care hospital
}

\author{
S. V. Nachiketha* \\ Associate Professor, Department of Obstetrics and Gynecology, Karnataka Institute of Medical Sciences, Hubli, \\ Karnataka, India
}

Received: 07 March 2017

Accepted: 14 March 2017

*Correspondence:

Dr. S. V. Nachiketha,

E-mail: drsvn1974@gmail.com

Copyright: ( $\odot$ the author(s), publisher and licensee Medip Academy. This is an open-access article distributed under the terms of the Creative Commons Attribution Non-Commercial License, which permits unrestricted non-commercial

\section{ABSTRACT}

Background: Hysteroscopy has been found useful to evaluate the problem of abnormal uterine bleeding. It helps to resolve this by direct view of uterus. It is useful in detecting endometrial hyperplasia. Objective of the study is to evaluate the role of Hysteroscopy in the diagnosis of patients with AUB and Correlate HPR findings.

Methods: Total 50 woman who presented with complaints of abnormal uterine bleeding were studied for one year from December 2012 to November 2013. The observations obtained were analyzed.

Results: Total of 50 women presenting with complaints of abnormal uterine bleeding were enrolled. Data obtained analyzed and final results and observations were tabulated pertaining to age, Chief complaints, Duration of symptoms, Menopause, Parity, Hysteroscopic/HPR findings, Accuracy obtained correlating with HPR.

Conclusions: Hysteroscopy is highly sensitive diagnostic procedure which not only provides useful information of the uterine cavity but also an ideal method for the evaluation of patients with abnormal uterine bleeding.

Keywords: Diagnostic procedure, Evaluation, Hysteroscopy, Uterine cavity

\section{INTRODUCTION}

Uterine bleeding is a normal physiologic episodic occurrence for most women. Its characteristics vary considerably. The broad range of normal variation causes difficulty in identifying abnormal patterns. The problem is that the uterine bleeding has a wide range of diagnostic possibilities and confusion is generated when review and reports fail to outline the diagnostic evaluation of patient who presents with abnormal uterine bleeding patterns. ${ }^{1,2}$

Dilatation and Curettage is a blind procedure and the endometrium has to be sent to the pathologist to study histological patterns. The co-operation of the pathologist is important. Ultrasonography clearly depicts the contour and the status of the ovary, but fails to provide adequate information regarding the endometrium. ${ }^{3}$
Hysteroscopy has ushered a new era in the evaluation of abnormal uterine bleeding. By direct visualization of the uterine cavity it is able to pin point the etiology in majority of the cases. It can detect endometrial hyperplasia accurately and aids in the early diagnosis of endometrial carcinoma and uterine polyps. ${ }^{4}$

Abnormal uterine bleeding is one of the most common complaints with which a patient presents to a Gynecologist. Dilatation and Curettage has long been the diagnostic gold standard for abnormal uterine bleeding. However, only $70-80 \%$ of the endometrium can be curetted. Polyps and sub mucous fibroids are frequently undetected by curettage alone. ${ }^{1}$ The judicious use of hysteroscopy to manage this medical entity adds a new dimension in handling this often perplexing problem. ${ }^{5}$ This study has been taken up to analyze the place of hysteroscopy in evaluation of AUB in terms of accuracy 
of hysteroscopic findings and the contribution of the procedure to clinical diagnosis. It also aims to correlate hysteroscopic findings with histopathological results.

\section{METHODS}

The present study was carried out in the Department of Obstetrics and Gynecology, from December 2012 to November 2013.

A total of 50 women who presented with complaints of abnormal uterine bleeding were studied.

\section{Inclusion criteria}

Pre and post-menopausal women reporting with AUB

\section{Exclusion criteria}

Women with AUB due to injuries of the vulva and vagina, pathology of the cervix and the Ovaries and not willing to participate in the study were excluded.

\section{Ethical clearance and informed consent obtained}

\section{Interventions}

Hysteroscopy was done in the hospital as an inpatient procedure under GA.

Normal Saline $(0.9 \%)$ was used as Distension medium.

\section{Procedure}

Under GA Hysteroscopy was done. Uterine cavity was visualized. The following points were noted:

- The nature of surface and color of endometrium

- The glandular openings.

- The vascular pattern.

- The tubal Ostia.

- Any other abnormalities.

\section{Statistical analysis}

The data was collected and entered. The data was analyzed using appropriate statistical tests. $\mathrm{P}$ value less than 0.05 was taken as statistically significant.

\section{RESULTS}

A total of 50 women presenting with complaints of abnormal uterine bleeding were enrolled.

All the women were subjected to hysteroscopy and pathological findings. In the present study $42 \%$ of the women were aged between 41 to 50 years and $34 \%$ between 31 to 40 years. The mean age was found to be $39.86 \pm 8.29$ years.
Table 1: Age distribution of study subjects.

\begin{tabular}{|l|l|l|}
\hline $\begin{array}{l}\text { Age group } \\
\text { (years) }\end{array}$ & Distribution $(\mathbf{n = 5 0})$ \\
\hline 21 to 30 & 9 & Percentage \\
\hline 31 to 40 & 17 & 18.00 \\
\hline 41 to 50 & 21 & 34.00 \\
\hline 51 to 60 & 2 & 42.00 \\
\hline 61 to 70 & 1 & 4.00 \\
\hline Total & $\mathbf{5 0}$ & 2.00 \\
\hline
\end{tabular}

Table 2: Chief complaints of study subjects.

\begin{tabular}{|lll|}
\hline \multirow{2}{*}{ Presentation } & Distribution $(\mathrm{n}=50)$ \\
\hline Menorrhagia & Number & Percentage \\
\hline Irregular cycles & 30 & 60.00 \\
\hline Polymenorrhagia & 9 & 18.00 \\
\hline Postmenopausal bleeding & 4 & 16.00 \\
\hline Menometrorrhagia & 3 & 8.00 \\
\hline Oligomenorrhagia & 3 & 6.00 \\
\hline Hypomenorrhoea & 2 & 4.00 \\
\hline
\end{tabular}

In the present study $60 \%$ of the women reported menorrhagia. The other complaints were irregular cycles $(18 \%)$, polymenorrhagia $(16 \%)$, postmenopausal bleeding $(8 \%)$, menometrorrhagia (6\%), oligomenorrhagia $(6 \%)$ and hypomenorrhoea (4\%).

Table 3: Duration of symptoms of study subjects.

\begin{tabular}{|lll|}
\hline Duration & Distribution $(\mathbf{n = 5 0})$ \\
\hline & Number & Percentage \\
\hline$<6$ months & 20 & 40.00 \\
\hline$>6$ months to 1 year & 24 & 48.00 \\
\hline$>$ 1 year & 6 & 12.00 \\
\hline Total & $\mathbf{5 0}$ & $\mathbf{1 0 0 . 0 0}$ \\
\hline
\end{tabular}

In this study $48 \%$ of the women had duration between more than six months to one year and $40 \%$ had duration of less than six months. However, $12 \%$ of the women reported duration of more than one year $(12 \%)$.

Table 4: Menopausal status of study subjects.

\begin{tabular}{|lll|}
\hline History & Distribution $(\mathbf{n = 5 0})$ \\
\hline Menopause & Number & Percentage \\
\hline Yes & 4 & 8.00 \\
\hline No & 46 & 92.00 \\
\hline Total & $\mathbf{5 0}$ & $\mathbf{1 0 0 . 0 0}$ \\
\hline
\end{tabular}

In the present study $8 \%$ of the women presented with postmenopausal bleeding.

In the present study parity status of three or more was noted in $48 \%$ of the women while parity status of two and one were noted in $30 \%$ and $16 \%$ respectively. However $6 \%$ of the women were nulliparous. 
Table 5: Parity wise distribution of study subjects.

\begin{tabular}{|lll|}
\hline Parity & Distribution $(\mathbf{n}=\mathbf{5 0})$ \\
\hline & Number & Percentage \\
\hline Nulliparous & 3 & 6.00 \\
\hline 1 & 8 & 16.00 \\
\hline 2 & 15 & 30.00 \\
\hline 3 or more & 24 & 48.00 \\
\hline Total & $\mathbf{5 0}$ & $\mathbf{1 0 0 . 0 0}$ \\
\hline
\end{tabular}

Table 6: Hysteroscopy findings of study subjects.

\begin{tabular}{|lcc|}
\hline Findings & Distribution $(\mathrm{n}=50)$ \\
\hline Normal Endometrium & 30 & Percentage \\
\hline Secretary endometrium & 16 & 32.00 \\
\hline Proliferative endometrium & 14 & 28.00 \\
\hline Endometrial hyperplasia & 8 & 16.00 \\
\hline Endometrial polyp & 6 & 12.00 \\
\hline Endometrial atrophy & 3 & 6.00 \\
\hline Sub mucous myoma 3 & & 6.00 \\
\hline Total & $\mathbf{5 0}$ & $\mathbf{1 0 0 . 0 0}$ \\
\hline
\end{tabular}

In the present study hysteroscopy findings revealed $60 \%$ of the women with normal endometrium. The other findings included endometrial hyperplasia (16\%), endometrial polyp (12\%), endometrial atrophy (6\%) and sub mucous myoma $(6 \%)$.

Table 7: Histopathology findings of study subjects.

\begin{tabular}{|lll|}
\hline \multirow{2}{*}{ Findings } & \multicolumn{2}{c|}{ Distribution $(\mathbf{n}=50)$} \\
\hline Normal Endometrium & 33 & 66.00 \\
\hline $\begin{array}{l}\text { Proliferative } \\
\text { endometrium }\end{array}$ & 18 & 36.00 \\
\hline Secretary endometrium & 15 & 30.00 \\
\hline Endometrial hyperplasia & 8 & 16.00 \\
\hline Endometrial atrophy & 4 & 8.00 \\
\hline Endometrial polyp & 2 & 4.00 \\
\hline Sub mucous Myoma & 2 & 4.00 \\
\hline Endometritis & 1 & 2.00 \\
\hline Total & $\mathbf{5 0}$ & $\mathbf{1 0 0 . 0 0}$ \\
\hline
\end{tabular}

In this study the histopathological examination showed normal endometrium in $66 \%$ of the women.

Table 8: Age wise hysteroscopy findings of study subjects.

\begin{tabular}{|c|c|c|c|c|c|c|c|c|c|}
\hline Age group (years) & 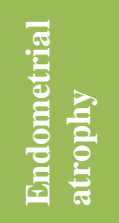 & 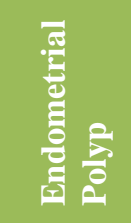 & 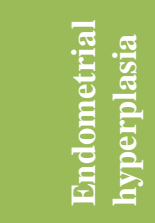 & 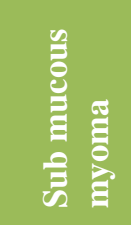 & 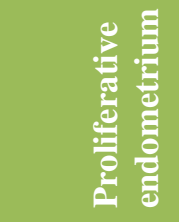 & & 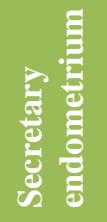 & & $\frac{\overrightarrow{5}}{\stackrel{0}{0}}$ \\
\hline$<30$ & 0 & 1 & 0 & 1 & 4 & 3 & & 9 & \\
\hline 30 to 40 & 0 & 4 & 0 & 0 & 6 & 7 & & 17 & \\
\hline 41 to 50 & 1 & 2 & 7 & 2 & 5 & 4 & & 21 & \\
\hline 51 to 60 & 1 & 0 & 1 & 0 & 0 & 0 & & 2 & \\
\hline$>60$ & 0 & 0 & 0 & 0 & 1 & 0 & & 1 & \\
\hline Total & 2 & 7 & 8 & 3 & 16 & 14 & & 50 & \\
\hline
\end{tabular}

The other findings were endometrial hyperplasia in $16 \%$, endometrial atrophy in $8 \%$, endometrial polyp and sub mucous myoma in $4 \%$ each, and endometritis in $2 \%$.

Table 9: Accuracy of hysteroscopy considering histopathology as reference standard.

\begin{tabular}{|llll|}
\hline Hysteroscopy & \multicolumn{2}{l|}{ Histopathology } & Total \\
\hline Abnormal & 15 & 5 & 20 \\
\hline Normal & 2 & 28 & 30 \\
\hline Total & $\mathbf{1 7}$ & $\mathbf{3 3}$ & $\mathbf{5 0}$ \\
\hline
\end{tabular}

Sensitivity $=88.24 \% ; \quad$ Specificity $=84.85 \% ; \quad P P V=75 \%$; $\mathrm{NPV}=93.33 \% ; \quad \mathrm{p}<0.001 ; \quad$ Diagnostic $\quad$ accuracy $=84 \%$; Kappa $=0.701$; Standard error of Kappa $=0.104$ (95\% CI 0.4980.904).

In the present study 21 women were aged between 41 to 50 years. Among them, 7 women were diagnosed to have endometrial hyperplasia, 2 each with endometrial polyp and sub mucous myoma and one with endometrial atrophy while 9 women had normal findings on hysteroscopy.

In this study histopathological findings showed 17 women with abnormal findings. Of these, 15 were abnormal on hysteroscopy and 2 were normal. The sensitivity of hysteroscopy in predicting accurate diagnosis was $88.24 \%$ and diagnostic accuracy was found to be $84 \%$. The Kappa statistics showed with 'good' agreement between hysteroscopy and histopathology (Kappa value-0.701). Maximum correlation that is, 100\% correlation of hysteroscopy and histopathology was noted with simple hyperplasia, sub mucous myoma, endometrial polyp and cystoglandular hyperplasia. In cases with endometrial atrophy $75 \%$ correlation was found and in normal cases $72 \%$ correlation was noted. 
Table 10: Correlation of hysteroscopy and histopathological findings.

\begin{tabular}{|c|c|c|c|c|c|c|c|c|c|c|}
\hline Histopathological diagnosis & $\begin{array}{l}\text { है } \\
\frac{0}{5} \\
\frac{5}{5} \\
\text { है } \\
\text { है }\end{array}$ & 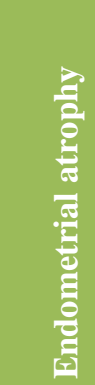 & $\begin{array}{l}\frac{2}{8} \\
\frac{2}{8} \\
\frac{0}{3} \\
\frac{8}{0} \\
\frac{0}{0} \\
\frac{0}{0}\end{array}$ & 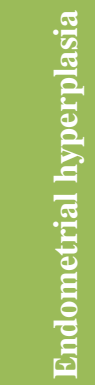 & 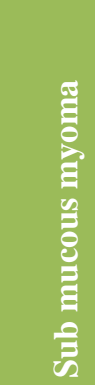 & 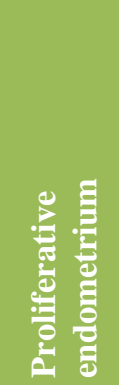 & 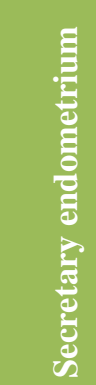 & $\begin{array}{l}\bar{\sigma} \\
\vec{\theta}\end{array}$ & 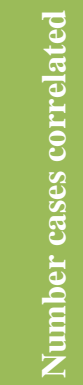 & 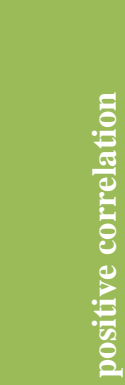 \\
\hline Cystoglandular hyperplasia & 1 & 0 & 0 & 1 & 0 & 0 & 0 & 1 & 1 & $100 \%$ \\
\hline Endometrial atrophy & 4 & 3 & 0 & 0 & 0 & 0 & 1 & 4 & 3 & $75 \%$ \\
\hline Endometrial polyp & 1 & 0 & 1 & 0 & 0 & 0 & 0 & 1 & 1 & $100 \%$ \\
\hline Endometritis & 1 & 0 & 0 & 0 & 0 & 0 & 1 & 1 & 0 & $0 \%$ \\
\hline Simple hyperplasia & 6 & 0 & 0 & 6 & 0 & 0 & 0 & 6 & 6 & $100 \%$ \\
\hline Sub mucous myoma & 1 & 0 & 0 & 0 & 1 & 0 & 0 & 1 & 1 & $100 \%$ \\
\hline Normal & 36 & 0 & 5 & 1 & 2 & & 12 & 36 & 26 & $72 \%$ \\
\hline Total & $\mathbf{5 0}$ & 3 & 6 & 8 & 3 & 16 & 14 & $\mathbf{5 0}$ & 38 & $76 \%$ \\
\hline
\end{tabular}

\section{DISCUSSION}

Abnormal uterine bleeding is a disease of childbearing and perimenopausal age group. The number decreases towards both ends of life. In the present study the commonest age group was between 41 to 50 years comprised of $42 \%$ of the women followed by 31 to 40 years with $34 \%$ of the women and the mean age was $39.86 \pm 8.29$ years. These findings suggest that, there is higher frequency of abnormal uterine bleeding in fourth and fifth decade. These findings were consistent with a recent study from Andhra Pradesh by Sunitha $\mathrm{C}$ et al where authors reported $40 \%$ of the women between 30 to 39 years and $36 \%$ in the age range of 40 to 49 years. ${ }^{2} \mathrm{~A}$ recent study from Maharashtra, India by Anvilkar AR et al also reported $83 \%$ patients were in the age group 30 to 50 years. The mean age of $39.86 \pm 8.29$ years noted in the present study was comparable with a recent study from Bangalore by Varadrajan $\mathrm{R}$ et al which reported the mean age of 43.64 years. $^{3,4}$

Most of the women presented with menorrhagia (60\%) and the next common presentation was irregular cycles $(18 \%)$ followed by polymenorrhagia (16\%). However, few reported postmenopausal bleeding (8\%), menometrorrhagia (6\%), oligomenorrhagia $(6 \%)$ and hypomenorrhoea $(4 \%)$ in their studies. The clinical presentation observed in the present study was close to a study from Andhra Pradesh by Sunitha C et al. which reported majority of the patients with menorrhagia (46\%) followed by post-menopausal bleeding (32\%) while polymenorrhagia and metrorrhagia were present in $12 \%$ and $10 \%$ of the women. ${ }^{2} 23 \%$ cases. In a study from
Mangalore by Nandan $\mathrm{N}$ et al. $^{5} 16.6 \%$ had postmenopausal bleeding \& the rest had other menstrual abnormalities as an indication for hysteroscopy. Among which, menorraghia $(49.7 \%)$ being the commonest complaint.

Most of the women (48\%) reported six months to one year duration of symptoms while in $40 \%$ of the women the duration was less than six months. Prolonged duration of symptoms that is one year or more was noted in $12 \%$ of the women. A similar study of 50 patients from Andhra Pradesh by Sunitha C et al, majority, 21 (42\%) had symptoms for more than 1 year, 15 patients $(30 \%)$ had symptoms for 6 months to 1 year and 14 patients (28\%) had symptoms for less than 6 months. These findings were comparable with the present study. ${ }^{2}$

With regard to obstetric history menopause was noted in $8 \%$ of the women and majority that is, $94 \%$ of the women reported multi parity indicating higher rate of AUB in women with multiparity. A study from Mangalore by Nandan $\mathrm{N}$ et al, most of the patients were multiparous $(90.9 \%)$. Recently another study from Maharashtra, India by Anvilkar AR et al reported that, $95 \%$ of the women were multiparous. The high incidence of AUB in multiparous women as in our study (94\%) has also been reported by Pilli et al $(87 \%){ }^{3,5,6}$

Hysteroscopy findings revealed $60 \%$ of the women with normal endometrium. The rate of normal findings observed in the present study was consistent with a study from Andhra Pradesh by Sunitha $\mathrm{C}$ et al where authors noted $54 \%$ of the patients with normal findings. In this study most of the women were diagnosed to have 
endometrial hyperplasia (16\%) followed by endometrial polyp (12\%), endometrial atrophy (6\%) and Sub mucous myoma $(6 \%)$. Similar diagnosis pattern was noted in a study from Andhra Pradesh by Sunitha C et al where most common abnormality was endometrial hyperplasia (20\%), followed by endometrial polyps (14\%), sub mucous myomas (4\%), endometrial hypertrophy $(6 \%)$, endometritis $(2 \%) .^{2}$

We found that $60 \%$ of cases as normal and remaining as abnormal. Similar findings were reported by Gimpelson, Sheth, Parasnis, Neumann, Trotsenburg, and Garito. ${ }^{7-12}$

The histopathological examination showed normal endometrium in $66 \%$ of the women. The other findings were endometrial hyperplasia in $16 \%$, atrophy in $8 \%$, endometrial polyp and Sub mucous Myoma in $4 \%$ each, and Endometritis in 2\%. In a recent study from Mangalore by Nandan $\mathrm{N}$ et al, histopathological findings were normal in $48.6 \%$ of the women and Hyperplasia was diagnosed in $12.3 \%$ and other diagnosis were Atrophy in $4 \%$, Polyp in $3.4 \%$ while cancer and pill endometrium were noted in $6.9 \%$ and $1.7 \%$ of the women which were not diagnosed in any of the patients in this study. Histopathological findings of endometrium in various studies reveal about half of the patients with AUB with normal proliferative or secretary endometrium and endometrial hyperplasia as the most common abnormality. Simple hyperplasia without atypia was the most common type.,

In this study based on histopathological findings, 17 women had abnormal findings of which, 15 had abnormal findings on hysteroscopy and normal findings were noted in 2 women. The sensitivity of hysteroscopy in predicting accurate diagnosis was $88.24 \%$ with specificity of $84.85 \%$, PPV of $75 \%$, NPV of $93.33 \%$ and diagnostic accuracy was found to be $84 \%$. The Kappa statistics showed with 'good' agreement between hysteroscopy and histopathology Kappa $=0.701$; Standard error of Kappa $=0.104$ (95\% CI 0.498-0.904). A recent study by Varadarajan $\mathrm{R}$ et al reported $96 \%$ sensitivity of hysteroscopy. The sensitivity and specificity observed in the present study is comparable with these studies in the literature. ${ }^{4,9}$

We can say that the hysteroscopy is a valid diagnostic tool in detecting the cause of postmenopausal bleeding. In our study, three cases of endometrial polyp were diagnosed as sub mucous myoma by hysteroscopy which can be explained by difficulty to distinguish small sub mucous myoma type 2 from a large sessile polyp. There were also 6 cases of endometrial hyperplasia and atrophy diagnosed by hysteroscopy that proved to be normal findings after the histological examination, but there were no cases of intrauterine pathology that were missed by hysteroscopy and later appeared at histological finding. The majority of studies, as well as ours, show that endometrial cancer has specific hysteroscopic appearance, so it is difficult to hysteroscopically declare it normal and in combination with biopsy the possibility of error is $0 \%$.

Overall the study has proved the utility of hysteroscopy in the diagnosis of various endometrial and intrauterine lesions, with higher accuracy. Thus hysteroscopy should be used as a first line diagnostic modality in patients complaining of abnormal uterine bleeding.

\section{CONCLUSION}

Adequate diagnosis is of utmost importance for the selection of relevant treatment and management of abnormal uterine bleeding so as to avoid unnecessary surgical procedures. Hysteroscopy is highly sensitive diagnostic procedure which not only provides useful information about the uterine cavity but also an ideal method for the evaluation. Further, endometrial biopsy improves the diagnostic accuracy of hysteroscopy in detecting endometrial pathology.

Funding: No funding sources Conflict of interest: None declared

Ethical approval: The study was approved by the Institutional Ethics Committee

\section{REFERENCES}

1. Baggish MS. Operative Hysteroscopy. In: Rock JA, Jones HW III, editors. TeLinde's Operative Gynecology. 9th ed., Philadelphia: Lippincott Williams and Wilkins; 2003;379-411.

2. Sunitha C, Somalatha R. Clinical study of diagnostic hysteroscopy in abnormal uterine bleeding and its histopathological correlation. IOSR J Dental Medical Sci. 2013;5(3):43-6.

3. Anvilkar AR, Ramteerthakar NA, Sulhyan KR. Abnormal uterine bleeding - A clinico-pathological study of 160 cases. Asian J Med Res 2013;2(1):15-8.

4. Varadrajan R, Sreekantha SM. Role of hysteroscopy in abnormal uterine bleeding in premenopausal age group. J Evolution Med Dental Sci. 2013;2(10):1504-8.

5. Nandan N, Manjeera L, Rai S, Gowri M. Diagnostic hysteroscopy in abnormal uterine bleeding and its histopathologic correlation: Our experience. Nitte Uni J Health Sci. 2013;3(2):13-7.

6. Pilli GS, Sethi B, Dhaded AV. Dysfunctional uterine bleeding (Study of 100 cases). J Obstet Gynecol India. 2002;52(3):87-9.

7. Gimpelson RJ, Rappold HO. A comparative study between panoramic hysteroscopy with directed biopsies and dilatation and curettage: a review of 276 cases. Am J Obstet Gynecol. 1988;158(3.1):489-92.

8. Sheth SS, Nerurkar NM, Mangeshkar PS. Hysteroscopy in abnormal uterine bleeding. J Obstet Gyn India. 1990;40:451.

9. Parasnis HB, Parulekar SV. Significance of negative hysteroscopic view in abnormal uterine bleeding. J Postgrad Med. 1992;38:62-4. 
10. Neumann T, Astudillo J. Hysteroscopic study in patients with abnormal uterine bleeding. Rev Chil Obstet Gynecol. 1994;59:349-52.

11. Van Trotsenburg M, Wieser F, Naegle F. Diagnostic hysteroscopy for the investigation of abnormal uterine bleeding in premenopausal patients. Contrib Gynecol Obstet. 2000;20:21-6.
12. Garuti G, Sambruni I, Colonnelli M, Luerti M. Accuracy of hysteroscopy in predicting histopathology of endometrium in 1500 women. J Am Assoc Gynecol Laparosc 2001;8:207-13.

Cite this article as: Nachiketha SV. Hysteroscopic assessment of patients with abnormal uterine bleeding: a prospective study at a tertiary care hospital. Int J Reprod Contracept Obstet Gynecol 2017;6:1326-31. 